\title{
An Enterprise Architecture Framework for Mobile Commerce
}

\author{
Khawar Hameed ${ }^{1}$, Hanifa Shah ${ }^{2}$, Kamran Ahsan $^{3}$ and Weijun Yang ${ }^{4}$ \\ 1234 Faculty of Computing, Engineering and Technology, \\ Staffordshire University, \\ Stafford, United Kingdom
}

\begin{abstract}
The increasing deployment of mobile technologies across industry sectors is creating fertile ground for organisations to exploit new revenue streams generated from applications that exploit the mobile ecosystem. M-Commerce has been recognised as a key driving force of next generation computing and industry analysts such as IDC have predicted revenue growth arising from m-commerce to far exceed US\$27 billion by the end of the decade [1]. Mobility has, without doubt, underpinned the current wave and generation of computing systems resulting in the concept and practicality of mobile solutions becoming embedded as natural or inherent ones that support the daily functions of individuals and corporations. This paper explores an approach to encapsulating the m-commerce ecosystem through the perspective of an enterprise architecture framework.
\end{abstract}

Keywords: Mobility, Mobile Commerce, Mobile Applications, Mobile Innovation, Mobile Services

\section{Introduction}

The phenomenon of mobility has driven an evolution and revolution of technologies and new ways of working, exploiting the practice of anytime, anyplace, anyhow computing whilst gaining critical mass as a research discipline and paradigm - the study of which has provided a grounding for conceptual and theoretical perspectives that allow framing and discussion of mobility [2] [3]. Mobile commerce has created a wide range of business opportunities - the spectrum of which includes the transformation of mobile network operators to go beyond the provision of core voice services to the delivery of value added services and service aggregation that provide comprehensive consumer packages [4], the emergence of business models to develop and deploy mobile applications (such as the Apple 'App' Store, the $\mathrm{O}_{2}$ Litmus programme, and the Sony Ericsson Developer World most of which are based on shared revenue distribution through sales through the respective hosting channels. Furthermore, open programmes and platforms such as Android (Google) are likely to contribute to the enlargement of the developer community that seeds the growth of mobile applications. With the supply chain of mobile computing and commerce, a range of opportunities exist for contributing parties to collaboration to provide value-added solutions based on new relationship types, rules and ecosystems [5] further enhancing the composite capability and reach of service providers into new market areas. Beyond service providers, the ease of access, penetration, and diffusion of mobile technologies has enabled individual sectors and organisations therein to apply the concepts and practice of mobility to create innovative domain-specific m-commerce applications that leverage the specific nuances associated with those domains resulting in value-added solutions for end-users and new revenue-generating opportunities for business. Examples of these include mobile location-based tourism, travel and navigation systems, m-ticketing and booking applications. Beyond the core commercial imperative of increased revenue generation, the application of mobile computing and principles of m-commerce also underpin the development of private and public sector mobile applications that aim to reduce operating costs, enhance efficiency and provide better platforms for engaging the end-user population. Basole [2] presents an Enterprise Mobility Continuum that frames mobile solutions from point-specific solutions to those that diffuse across entire organisations to create stakeholder value. Across and throughout the complex m-commerce ecosystem the question arises regarding the construction of m-commerce solutions and how these are best approached.

The increasing attention to business underpinned by mobility, mobile services, mobile applications, and technologies has become a major driver for the development of m-commerce systems. This growing trend has become a focus for a significant number of organisations. This paper proposes that in developing $\mathrm{m}$ commerce systems organisations need to establish an enterprise architecture for m-commerce. The rationale for this is rooted in the need to develop a holistic and integrated view of strategic direction relating to $\mathrm{m}$ commerce which will enable a coordinated and controlled approach that reduces complexity and yields effective systems based on the structured integration of services, practices and technology resources. In doing so, the potentially complex universe of discourse associated with 
mobility is harnessed to produce and organisational asset to drive the development of m-commerce.

The next section proposes a framework to establish such an enterprise architecture for mobile commerce. Firstly, an enterprise architecture framework for mobile commerce is presented followed by a brief view of associated issues concerned with method.

\section{An Enterprise Architecture (EA) Framework for Mobile Commerce}

An EA framework provides the basis or template for the creation and establishment of enterprise architecture. Zachman [6] is credited with developing the discipline of enterprise architectures as a concern for both researchers and practitioners. An enterprise architecture framework is essentially a meta-construct used to define the scope of the associated architecture and how the areas of the architecture relate to each other [7]. An architecture can be considered analogous to a blueprint or plan of a building structure, where different perspectives may exist and each perspective contains structures that demonstrate inter-relationships based upon some predefined constraint and yield a solid foundation and approach upon which the building is constructed.

Generally speaking, the EA framework defines the scope of the resulting architecture, which typically includes a business view, information integration, application-level views, and technology infrastructures. Definitions of each view may include more refined constructs and relationships at a lower level of granularity.

The application of an EA approach is considered relevant and appropriate since the ecosystem within which the development of m-commerce solutions occurs comprises a set of interrelated perspectives based upon the integration of mobile devices, technologies, and business processes [8]. Therefore, an EA framework for mobile commerce can be considered to address, at least, the scope of architecture covering the business level/view, the application level and the technology infrastructure level.

In each level of our proposal, core components have been identified. These are: a business model of m-commerce (business level), supply chain of m-commerce (supply chain level), m-commerce applications (application level) and technology infrastructure for m-commerce (technology level). Our research has shown that integration of core EA approaches with m-commerce is relatively sparse, whereas literature in both contributing areas is substantial. Furthermore, Leist \& Zellner [9] state that "as information systems grown in complexity and scope the need for a comprehensive and consistent approach in modelling these systems becomes of paramount importance." Basole [2] recognises that businesses are "just beginning to recognise the importance and potentially transformative impact of enterprise mobility." Given this our approach to applying EA principles to m-commerce appears well-grounded. A proposed Enterprise Architecture Framework for mobile commerce is shown in Figure 1.

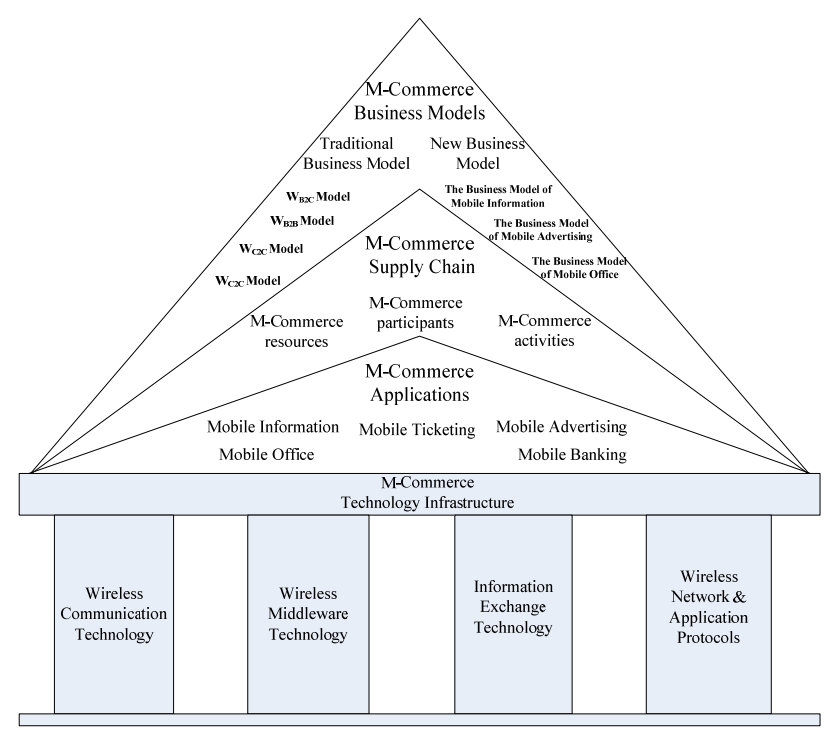

Fig. 1 An Enterprise Architecture Framework for Mobile Commerce

\subsection{First Level: M-Commerce Business Models}

Figure 1 shows the first (topmost) level in our Enterprise Architecture framework for m-commerce relating to business models. This level is identified as the first level in the EA framework and provides a description of the roles and relationships of an organisation, its customer, partners and suppliers and stakeholders, as well as the flows of goods, information and money between these parties and the main benefits for those involved [10]. The stakeholder transactional models are based upon those presented by Coursaris \& Hassanein [11] and are divided into four models (i) wireless Business-to-Consumer $\left(\mathrm{W}_{\mathrm{B} 2 \mathrm{C}}\right)$ model; (ii) a wireless Consumer-to-Business ( $\left.\mathrm{W}_{\mathrm{C} 2 \mathrm{~B}}\right)$ model; (iii) a wireless Consumer-to-Consumer $\left(\mathrm{W}_{\mathrm{C} 2 \mathrm{C}}\right)$ model; and (iv) a wireless Consumer-to-Self $\left(\mathrm{W}_{\mathrm{C}}{ }^{2}\right)$ model. These models mainly describe business activities between the contributing parties, and the specific nature of these. The abstraction of these models provides a basis for higherlevel understanding of the spectrum of stakeholders and relationships at the topmost level of the architecture.

Other business models of mobile commerce attempt to address the complexities associated with the m-commerce ecosystem comprising different participants (such as mobile consumers, network operators, service providers, 
application developers, content providers and technology providers) and encompass the types of services and sources of profits. In addition, models describe operations and processes relating to mobile growth, value-added benefits, revenue models and return on investment, and the transfer of benefits across stakeholders for mutual gain [12].

During the development of our framework we reviewed models broadly associated with the business models for mobile information, mobile advertising and for mobile office work. Typical characteristics of these were associated with relationships between content providers, network operators and service providers for direct gain through revenue opportunities from mobile consumers and shared distribution amongst stakeholders and participants. Interestingly, one specific finding was that, "mobile consumers represent the only sustainable revenue source for participants" [13].

From the characteristics identified, it is seen that business models for mobile commerce are helpful in enabling organisations to increase the possibilities for increasing revenue and profit, and enhancing competitiveness. Taking Vodafone Group Plc [14] as a typical example rather complex business activities can be observed where the business acts as wireless network operator providing information transmission services for its customers whilst also acting as a content or service providers of specific service content for its customers such as music downloading, online gaming, e-mail and location-based information. In this and other similar cases the business models appear not to be mutually exclusive (e.g. single and independent $\mathrm{W}_{\mathrm{B} 2 \mathrm{C}}, \mathrm{W}_{\mathrm{C} 2 \mathrm{~B}}, \mathrm{~W}_{\mathrm{C} 2 \mathrm{C}}, \mathrm{W}_{\mathrm{C}}{ }^{2}$ business models) [11]. Thus, encapsulating the diverse stakeholder groups and associated mobile information needs can be seen as providing competitive advantage and market diversification.

\subsection{Second Level: The Supply Chain of Mobile Commerce}

Figure 1 shows the second level in the Enterprise Architecture framework for mobile commerce and is concerned with the supply chain. The materialisation of business models for m-commerce depends on a complex chain of business relationships between participants of the supply chain [12]. The supply chain for m-commerce is therefore identified as the second and supporting level in the enterprise architecture framework.

This supply chain for m-commerce can be seen as rooted in mobile telecom markets, within which a variety of participants possess resources, perform activities, and are in relationships that are established or evolving in delivering an end-to-end service [15]. However, given the increasing diversity of applications, services and associated information delivery, this supply chain is being extended to include a spectrum of market areas which, when aggregated provide value-added services to the mobile user.

The core elements of the m-commerce supply chain include mobile commerce participants, mobile commerce resources and mobile commerce activities. Mobile commerce participants are a major driving force behind the m-commerce supply chain [13]. Mobile commerce participants fundamentally include mobile consumers, wireless network providers, content provide, service providers, application developers and technology providers - all of whom engage in a business-oriented relationship and, in the specific case of m-commerce, one that is focussed on commercial gain for service delivery participants. For example, the shared/distributed revenue approach entails the wireless network providers delivering part of that revenue to other participants in the supply chain - such as content providers and other service providers.

\subsection{Third Level: Mobile Commerce Applications}

The third level of the framework is concerned with mobile commerce applications. Because an organisation uses mobile applications to support and deliver its business models through the supply chain, mobile applications are seen as the tangible end-user vehicles that mechanise and enable the m-commerce transaction. Mobile applications are therefore identified at the third level in the Enterprise Architecture framework for m-commerce.

M-commerce applications can be broadly categorised as communication applications, information applications, entertainment applications and commerce applications [11]. Five main application types were identified: mobile ticketing, mobile advertising, mobile information, mobile banking and mobile office applications. These were found to support the key business models and imperatives (revenue generation or cost reduction) and were constructed using the supply chain to deliver an aggregated service. The constantly developing landscape of mobile technologies, and more specifically application capability, raises a proposition of re-aligning business models and supply chains to fully leverage the potential of that change - thus suggesting a commercially synergistic relationship (in this case, the applications and technology forcing a re-evaluation of the business models and supply chain) . 


\subsection{Fourth Level: The Technology Infrastructure for Mobile Commerce}

The fourth level of the framework is concerned with technology infrastructure for m-commerce. This includes wireless communication technology, wireless middleware technology, information exchange technology, wireless network \& application protocols and mobile security technology. Essentially, these are the core technological components and infrastructures that enable mobile users in their environments. These technologies support upper levels of the framework (m-commerce business models, m-commerce supply chain, and m-commerce applications).

\section{Method}

In order to materialise a specific architecture from the enterprise architecture framework an associated method is required. The method provides a step-by-step description of how to establish the architecture [7]. In context of the proposed framework, a five-step approach is proposed based upon five generic steps [16] adapted to suit the framework-specific needs. Our current research focuses on the development of the m-commerce enterprise architecture framework and the method associated with this is in embryonic form. Nevertheless, views and expectations are that this will focus on internal knowledge audits to determine organisational readiness and mobile strategies, a series of data collection methods that aim to elicit the type of existing of new applications that can be mobilised in context of m-commerce, the skills base, and the technology/resource levels within the organisation, and levels of innovation. Other aspects are expected to address appropriate business planning tools, modelling techniques and notations that apply across the four levels of the framework and incorporate the modelling of mobility in context of mobile commerce opportunities. Technical limitations of mobile devices and wireless communications, business concerns and legal constraints complicate the practical use of mobile commerce [17]. Therefore, these also provide the impetus of developing appropriate methods that address these concerns. In all these cases organisations may have existing approaches and techniques that might be used a part of the method.

\section{Validation}

To validate the proposed framework a questionnaire was developed to test the overall construct of the framework, its direct relevance to businesses, and to seek the views that might be incorporated in its refinement. The survey aimed to elicit initial and relatively informal feedback and as such was constructed to provide qualitative feedback that would enable scope for interpretation and discussion. Three organisations (anonymity maintained) participated in the survey. Questions were asked in two parts (EA Framework for M-Commerce \& EA Method for MCommerce) and sought views on the following areas and propositions:

\subsection{The Business Model for M-Commerce}

- A1: The positioning of the business model for mcommerce at the first (topmost) level in the EA Framework

- A2: The role of a business model for m-commerce to describe how organisations create and realise genuine benefit from mobile commerce activities.

- A3: The division of an m-commerce business model into a Wireless Business-to-Consumer model, Wireless Consumer-to-Business model, Wireless Consumer-to-Consumer model, and Wireless Consumer-to-Self model [11].

- A4: The composition of a business model for mcommerce to include the source of profits, mobile services and supply chain participants.

- A5: The choice of novel or more recent business model approaches over traditional business models for m-commerce.

\subsection{The Supply Chain for M-Commerce}

- A6: The positioning of the supply chain model for mcommerce at the second level in the EA Framework.

- A7: That a good supply chain for m-commerce can streamline business processes for m-commerce.

- A8: That the supply chain for m-commerce includes m-commerce participants, m-commerce resources and m-commerce activities.

- A9: That the m-commerce participants are a major driving force behind the supply chain of $\mathrm{m}$ commerce.

\subsection{M-Commerce Applications}

- A10: The positioning of m-commerce applications at the third level in the EA Framework.

- A11: M-commerce applications are influenced by the business model and supply chain for m-commerce.

- A12: M-commerce applications need be supported by reliable m-commerce technology 


\subsection{Technology Infrastructure for M-Commerce}

- A13: The positioning of technology infrastructure for m-commerce at the final level (bottom) in the EA Framework.

- A14: The role of mobile communication technologies in offering message or wireless data capability.

- A15: That wireless middleware technology supports the development and operation of m-commerce applications.

- A16: Information exchange technologies are necessary for m-commerce applications and mobile devices.

- A17: That wireless network and application protocols can support the delivery of web-based information.

\subsection{EA Method for M-Commerce}

- B1: The positioning of data collection (knowledge audit) as a first step in an EA method for m-commerce.

- B2: Data collection should comprise identification of $\mathrm{m}$-commerce components and also possible obstacles or restrictions in m-commerce.

- B3: That defining the purposes of an EA for mcommerce is defined as the second step.

- B4: That establishing an EA (schema) for mobile commerce is defined as the third step.

- B5: That an EA framework of m-commerce needs be modelled by software tools.

- B6: That tool selection is defined as the finall step.

\section{Results}

A 3 scale scoring system was used and responses constrained to Accept (3), Neither/Neutral (2), and Not Accepted (1). All three participants responded and the summarised results for each participant are tabulated as shown.

\begin{tabular}{|c|c|}
\hline \multicolumn{2}{|c|}{ Establishing Enterprise Architecture (EA) for Mobile Commerce (M-Commerce) } \\
\hline \multicolumn{2}{|c|}{ Section A: An EA Framework of M-Commerce } \\
\hline $\begin{array}{l}\text { The Business Model of } \\
\text { M-Commerce: }\end{array}$ & $\begin{array}{c}\text { Total scale: }(1-15) \\
A 1:(3)+A 2:(3)+A 3:(2)+A 4:(3)+A 5:(3)=14\end{array}$ \\
\hline $\begin{array}{l}\text { The Supply Chain of } \\
\text { M-Commerce: }\end{array}$ & $\begin{array}{c}\text { Total scale: }(1-12) \\
A 6:(3)+A 7:(3)+A 8:(3)+A 9:(2)=11\end{array}$ \\
\hline $\begin{array}{l}\text { M-Commerce } \\
\text { Applications: }\end{array}$ & $\begin{array}{c}\text { Total scale: }(1-9) \\
\text { A10: }(3)+A 11:(2)+A 12:(3)=8\end{array}$ \\
\hline $\begin{array}{l}\text { Technology Infrastructure } \\
\text { of M-Commerce: }\end{array}$ & $\begin{array}{c}\text { Total scale: }(1-15) \\
A 13:(3)+A 14:(3)+A 15:(3)+A 16:(3)+A 17:(1)=13\end{array}$ \\
\hline Section & An EA Method for M-Commerce \\
\hline $\begin{array}{l}\text { The Steps in an EA Method for } \\
\text { M-Commerce: }\end{array}$ & $\begin{array}{c}\text { Total scale: }(1-18) \\
\mathrm{B} 1:(3)+\mathrm{B} 2:(3)+\mathrm{B} 3:(2)+\mathrm{B} 4:(3)+\mathrm{B} 5:(3)+\mathrm{B} 6:(2)=16\end{array}$ \\
\hline
\end{tabular}

Table 1: The total feedback score - Organisation 1

\begin{tabular}{|c|c|}
\hline \multicolumn{2}{|c|}{ Establishing Enterprise Architecture (EA) for Mobile Commerce (M-Commerce) } \\
\hline \multicolumn{2}{|c|}{ Section A: An EA Framework of M-Commerce } \\
\hline $\begin{array}{l}\text { The Business Model of } \\
\text { M-Commerce: }\end{array}$ & $\begin{array}{c}\text { Total scale: }(1-15) \\
A 1:(3)+A 2:(3)+A 3:(2)+A 4:(3)+A 5:(2)=13\end{array}$ \\
\hline $\begin{array}{l}\text { The Supply Chain of } \\
\text { M-Commerce: }\end{array}$ & $\begin{array}{c}\text { Total scale: }(1-12) \\
A 6:(3)+A 7:(3)+A 8:(3)+A 9:(2)=11\end{array}$ \\
\hline $\begin{array}{l}\text { M-Commerce } \\
\text { Applications: }\end{array}$ & $\begin{array}{c}\text { Total scale: }(1-9) \\
\text { A10: }(3)+A 11:(2)+A 12:(3)=8\end{array}$ \\
\hline $\begin{array}{l}\text { Technology Infrastructure } \\
\text { of M-Commerce: }\end{array}$ & $\begin{array}{c}\text { Total scale: }(1-15) \\
A 13:(3)+A 14:(3)+A 15:(3)+A 16:(3)+A 17:(2)=14\end{array}$ \\
\hline Section & : An EA Method for M-Commerce \\
\hline $\begin{array}{l}\text { The Steps in an EA Method for } \\
\text { M-Commerce: }\end{array}$ & $\begin{array}{c}\text { Total scale: }(1-18) \\
B 1:(3)+B 2:(3)+B 3:(2)+B 4:(3)+B 5:(3)+B 6:(3)=17\end{array}$ \\
\hline
\end{tabular}

Table 2: The total feedback score - Organisation 2 


\begin{tabular}{|c|c|}
\hline Establishing Enterprise $\mathrm{Ar}$ & $\begin{array}{l}\text { itecture (EA) for Mobile Commerce (M-Commerce) } \\
\text { An EA Framework of M-Commerce }\end{array}$ \\
\hline $\begin{array}{l}\text { The Business Model of } \\
\text { M-Commerce: }\end{array}$ & $\begin{array}{c}\text { Total scale: }(1-15) \\
\mathrm{A} 1:(3)+\mathrm{A} 2:(2)+\mathrm{A} 3:(2)+\mathrm{A} 4:(3)+\mathrm{A} 5:(3)=13\end{array}$ \\
\hline $\begin{array}{l}\text { The Supply Chain of } \\
\text { M-Commerce: }\end{array}$ & $\begin{array}{c}\text { Total scale: }(1-12) \\
\text { A6: (3) + A7: }(2)+A 8:(3)+A 9:(2)=10\end{array}$ \\
\hline $\begin{array}{l}\text { M-Commerce } \\
\text { Applications: }\end{array}$ & $\begin{array}{c}\text { Total scale: }(1-9) \\
\text { A10: }(3)+\text { A11: }(3)+A 12:(2)=8\end{array}$ \\
\hline $\begin{array}{l}\text { Technology Infrastructure } \\
\text { of M-Commerce: }\end{array}$ & $\begin{array}{c}\text { Total scale: }(1-15) \\
\text { A13: (3) + A14: (3) + A15: }(3)+A 16:(3)+A 17:(2)=14\end{array}$ \\
\hline \multicolumn{2}{|c|}{ Section B: An EA Method for M-Commerce } \\
\hline $\begin{array}{l}\text { The Steps in an EA Method for } \\
\text { M-Commerce: }\end{array}$ & $\begin{array}{c}\text { Total scale: }(1-18) \\
B 1:(3)+B 2:(3)+B 3:(2)+B 4:(2)+B 5:(3)+B 6:(2)=15\end{array}$ \\
\hline
\end{tabular}

Table 3: The total feedback score - Organisation 3

All 3 respondents scored highly regarding the business model component of the proposed framework, indicating its appropriate and relevant positioning. Similarly, responses regarding the supply chain model component of the framework scored highly. This again was interpreted as a positive response regarding its overall context and positioning. The scoring for m-commerce applications as part of the framework was slightly lower, although this was still deemed a positive response. Finally, the technology infrastructure level scored highly, again indicating an overall positive response. The overall interpretation was that the framework proposition was an appropriate and useful vehicle for the development of $\mathrm{m}$ commerce within organisations.

With respect to the method, all responded again scored this aspect highly thus indicating its potential relevance, value and use.

\section{Conclusions}

Mobile technology is continuing to play a significant role in providing efficient and effective means for organisations to broaden their revenue streams, and enhancing competitive positioning. There is no doubt that the mobile ecosystem creates many possibilities for the development of innovative solutions that create real value for end users whilst meeting real financial imperatives of service providers and stakeholders in the m-commerce supply chain. However, the mobile ecosystem is potentially complex and the universe of discourse created contains many interrelated components that span across financial, organisational, technological, and social boundaries. It is this that provides the impetus and rationale to focus on adopting an enterprise architecture framework approach to govern the development of $\mathrm{m}$ commerce systems and with a view to reducing complexity. It is also this that aims to enable organisations to adapt rapidly to mobile technologies, reap the affordances created through technology adoption, remain competitive - yet through a structured and framework-oriented approach that provides a baseline for pro-active transformation rather than a re-active and potentially chaotic and fragmented approach.

This paper has proposed an initial enterprise architecture framework for mobile commerce that aims to provide practitioners and researchers a platform for considering the development of m-commerce systems, and one which aims to influence both philosophical and practical approaches to building m-commerce systems. Initial response, albeit being based on limited demographics, has been positive and this provides motivation for future work. The framework proposition comprises four levels, each of which draws upon specific nuances associated with the mobile environment and each of which is constructed in context of other layers - thus demonstrating a frameworkoriented approach.

\section{Acknowledgments}

We would like to thanks the three organizations (anonymity maintained) for their participation in the survey.

\section{References}

[1] Mahatanankoon, P., Wen H.J., \& Lim,B. (2005) ConsumerBased m-commerce: Exploring Consumer Perception of Mobile Applications. Computer Standards \& Interfaces, 27(4), 347-357.

[2] Basole, Rahul C., Enterprise Mobility: Researching a New Paradigm. Information Knowledge Systems Management 7 (2008) 1-7.

[3] Kakihara, M., Sorensen, C. (2001) Expanding the 'Mobility' Concept. ACM SIGGROUP Bulletin. 22 (3) 33-37.

[4] Seybold, Andrew M., The Convergence of Wireless, Mobility, and the Internet and its Relevance to Enterprises. Information Knowledge Systems Management 7 (2008) 1123.

[5] McDowell, M., Business Mobility: A Changing Ecosystem. Information Knowledge Systems Management 7 (2008) 2537.

[6] Zachman, J.A., A Framework for Information Systems Architecture. IBM Systems Journal, Vol 26 (3) 1987.

[7] Scott A. Bernard, An Introduction to Enterprise Architecture, Second Edition, 2006. 
[8] N.Bandyo-padhyay, E-Commerce: Context, Concepts and Consequences, Published by McGraw-Hill Education, Second Edition, 2002.

[9] Zellner, S. L. A. G. (2006). Evaluation of current architecture frameworks. ACM, SAC'06, April, 23-27, 2006, Dijon, France.

[10] Giovanni Camponovo and Yves Pigneur, Business Model Analysis Applied To Mobile Business, The University of Lausanne, 2004.

[11] Coursaris \& Hassanein, Understanding m-commerce: A Consumer-centric Model, Degroote School of Business, McMaster University, 2006.

[12] WANG Yan \& GAO Yufei, Research on the Value Chain and Business Models for Mobile Commerce, Fudan University, 2004.

[13] Brian E.Mennecke and Troy J.Strader, Mobile Commerce: Technology, Theory, and Applications, Lowa State University, Published by Idea GroupInc, 2003.

[14] Vodafone, About Vodafone Power to You, from http://www.vodafone.com/start/about_vodafone, accessed November 13, 2009.

[15] Nan Si Shi, Wireless Communications and Mobile Commerce, Published in the United Kingdom by Idea Group Inc, 2004.

[16] Rob.C.Thomas, A Practical Guide for Developing an Enterprise Architecture, Federal Chief Information Officer Council, 2004.

[17] Keng Siau, Ee-Peng Lim, Zixing Shen, Mobile Commerce: Current States and Future Trends, University of NebraskaLincoln, USA, 2006.

Khawar HAMEED is a Principal Lecturer in the Faculty of Computing, Engineering \& Technology at Staffordshire University. His research is in the area of mobile and flexible working, enterprise architectures to support mobile information systems, and mobile learning. He has been a key driver in the adoption of mobile computing and technology within the Faculty's portfolio and has helped drive the development of undergraduate and postgraduate degrees in this technology area. He has contributed extensively to the development and delivery of externally funded projects and academic-industrial collaborations in mobile/wireless technology that aim to develop and enhance the collective intellectual capital that supports the growth of mobile and wireless systems as a discipline both within academia and in industry.

Hanifa SHAH is Professor of Information Systems and the Director of the Centre for Information, Intelligence and Security Systems at Staffordshire University. Her research interests and publications are in the areas of Knowledge Management, Information Systems Development, Enterprise Architecture, IT professionalism, and Mobile Technologies in Patient Processes.

Kamran AHSAN has an MSc in Mobile Computer Systems from Staffordshire University and MCS (Masters in Computer Science) from the University of Karachi. Kamran is a PhD researcher and lecturer in FCET (Faculty of Computing, Engineering and Technology) and a web researcher in the Centre for Ageing and Mental Health, Staffordshire University, UK. He has published several papers and has been involved in a number of UK funded research projects including KTP, NHS Trust, and Innovation Vouchers. He is Visiting Faculty at the University of Karachi. He is a consultant to businesses in IT applications, software development and web tools. His research interests are in mobile technology applications in healthcare including knowledge management.
Weijun YANG is a postgraduate candidate in Computer Science in the Faculty of Computing, Engineering \& Technology at Staffordshire University. His focus of work is in the area of enterprise architectures to support mobile commerce systems. Previously he worked as a technical consultant in performance and functional testing of IT systems, successfully developing and implementing performance optimization programs. His research interests are in the development of enterprise architectures and performance metrics for evaluating the function and effectiveness of mobile commerce solutions. 